2013

\title{
Structure and properties of $\mathrm{Mn} 4 \mathrm{Cl} 9$ : An antiferromagnetic binary hyperhalogen
}

Yawei Li

Peking University

Shunhong Zhang

Peking University

Qian Wang

Virginia Commonwealth University, Peking University, qwang@vcu.edu

Puru Jena

Virginia Commonwealth University, pjena@vcu.edu

Follow this and additional works at: http://scholarscompass.vcu.edu/phys_pubs

Part of the Physics Commons

$\mathrm{Li}$, Y., Zhang, S., \& Wang, Q., et al. Structure and properties of Mn4Cl9: An antiferromagnetic binary hyperhalogen. The Journal of Chemical Physics, 138, 054309 (2013). Copyright (C) 2013 American Institute of Physics.

\section{Downloaded from}

http://scholarscompass.vcu.edu/phys_pubs/180

This Article is brought to you for free and open access by the Dept. of Physics at VCU Scholars Compass. It has been accepted for inclusion in Physics Publications by an authorized administrator of VCU Scholars Compass. For more information, please contact libcompass@vcu.edu. 


\title{
Structure and properties of $\mathrm{Mn}_{4} \mathrm{Cl}_{9}$ : An antiferromagnetic binary hyperhalogen
}

\author{
Yawei Li, ${ }^{1}$ Shunhong Zhang, ${ }^{1}$ Qian Wang, ${ }^{1,2, a)}$ and Puru Jena ${ }^{2}$ \\ ${ }^{1}$ Center for Applied Physics and Technology, College of Engineering, Peking University, Beijing 100871, China \\ ${ }^{2}$ Department of Physics, Virginia Commonwealth University, Richmond, Virginia 23284, USA
}

(Received 26 October 2012; accepted 2 January 2013; published online 7 February 2013)

\begin{abstract}
Calculations based on density functional theory show that the structure of $\mathrm{Mn}_{4} \mathrm{Cl}_{9}$ anion is that of a $\mathrm{Mn}$ atom at the core surrounded by three $\mathrm{MnCl}_{3}$ moieties. Since $\mathrm{Mn}$ is predominantly divalent and $\mathrm{MnCl}_{3}$ is known to be a superhalogen with a vertical detachment energy (VDE) of $5.27 \mathrm{eV}, \mathrm{Mn}_{4} \mathrm{Cl}_{9}$ can be viewed as a hyperhalogen with the formula unit $\mathrm{Mn}\left(\mathrm{MnCl}_{3}\right)_{3}$. Indeed, the calculated VDE of $\mathrm{Mn}_{4} \mathrm{Cl}_{9}$ anion, namely $6.76 \mathrm{eV}$, is larger than that of $\mathrm{MnCl}_{3}$ anion. More importantly, unlike previously discovered hyperhalogens, $\mathrm{Mn}_{4} \mathrm{Cl}_{9}$ is the first such hyperhalogen species composed of only two constituent atoms. We further show that $\mathrm{Mn}_{4} \mathrm{Cl}_{9}$ can be used as a ligand to design molecules with even higher VDEs. For example, $\mathrm{Li}\left[\mathrm{Mn}\left(\mathrm{MnCl}_{3}\right)_{3}\right]_{2}$ anion has a VDE of $7.26 \mathrm{eV}$. These negatively charged clusters are antiferromagnetic with most of the magnetic moments localized at the Mn sites. Our studies show new pathways for creating binary hyperhalogens. (c) 2013 American Institute of Physics. [http://dx.doi.org/10.1063/1.4776217]
\end{abstract}

\section{INTRODUCTION}

Atoms, molecules, and clusters with high electron affinities (EA) are promising candidates for oxidizing systems with relatively high ionization potentials, and for the synthesis of organic superconductors as well as high energy density salts with unusual stability and desired properties. ${ }^{1-3}$ For example, the first compound containing noble gas atom, $\mathrm{Xe}^{+}\left[\mathrm{PtF}_{6}\right]^{-},{ }^{4}$ was synthesized by Bartlett using $\mathrm{PtF}_{6}$, the EA of which was estimated to be about $7.00 \mathrm{eV},{ }^{5}$ much larger than that of the $\mathrm{Cl}$ atom $(3.617 \pm 0.003 \mathrm{eV}) .{ }^{6}$ In 1981, Gutsev and Boldyrev coined the term superhalogen to describe such molecules and showed ${ }^{7}$ that these molecules could be created with the formula $\mathrm{MX}_{k+1}$ where $\mathrm{M}$ is a metal atom with maximal valence $k$ and $\mathrm{X}$ is a halogen atom. ${ }^{7}$ The vertical detachment energies (VDEs) of $\mathrm{MX}_{k+1}^{-}$were found to greatly exceed those of the halogen anions due to the delocalization of the additional electron over all the $\mathrm{X}$ atoms instead of a single $\mathrm{X}$ atom. ${ }^{8}$ Since then, numerous theoretical ${ }^{9-22}$ as well as experimental ${ }^{23-30}$ efforts have been devoted to find superhalogen anions with high VDE values. Much of the early work, however, concentrated on having a single metal atom at the core surrounded by halogen atoms. It was later shown that superhalogens can also be formed where the core consisting of a single metal atom is replaced by a metal-halogen complex. Since $\mathrm{MX}_{k}$ has a closed shell, it is natural to expect that the clusters with the formula of $\left(\mathrm{MX}_{k}\right)_{n}$ will exhibit singlet ground-states. Based on calculations and photoelectron spectroscopy (PES), ${ }^{31}$ Boldyrev and Wang found $\mathrm{M}_{n} \mathrm{X}_{n k+1}$ clusters form superhalogens, where $\mathrm{M}$ can be an alkaline and alkaline earth atom. ${ }^{32,33}$ In such polynuclear superhalogens, the EA increases with the size of the core. These findings paved

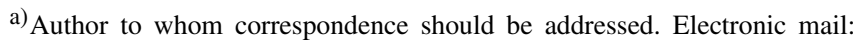
qianwang2@pku.edu.cn.
}

the way to design new systems, namely, $\mathrm{H}_{12} \mathrm{~F}_{13}^{-}$with a very large VDE value of $13.87 \mathrm{eV}^{34}$

Most of the earlier studies concentrated on the main group of elements for the polynuclear superhalogens. Recently, superhalogens with multiple transition metal atoms at the core are drawing more and more attention. For example, $\mathrm{Ta}_{3} \mathrm{~F}_{16}^{-}$was found to have a VDE value of $12.63 \mathrm{eV} .{ }^{20}$ This cluster can be viewed as $\left(\mathrm{TaF}_{5}\right)_{3} \mathrm{~F}^{-}$where the maximal valence of Ta is +5 . Similar properties have recently been observed in $\mathrm{Mn}_{x} \mathrm{Cl}_{y}$ clusters. We note that among all the transition metal elements, Mn plays a unique role in superhalogen studies due to its varying oxidation numbers from 0 to +7 or even negative. ${ }^{35}$ In particular, Mn exhibits a $3 d^{5} 4 s^{2}$ electronic configuration and in the +2 valence state forms the basis of molecular magnets with magnetic moments of $5 \mu_{\mathrm{B}}$ per atom. A search for magnetic superhalogens led to a study of the mass spectra of $\mathrm{Mn}_{x} \mathrm{Cl}_{y}$ clusters which revealed high peaks for $\left(\mathrm{MnCl}_{2}\right)_{x} \mathrm{Cl}^{-}(x=1-4)$ composition. ${ }^{36}$ Theoretical calculations performed for $x=1-3$ composition $^{36}$ showed that these peaks arise due to the anomalously high electron affinities and hence for the enhanced stability of these anions.

Recently, another new class of species was found to have electron affinities even larger than those of superhalo-

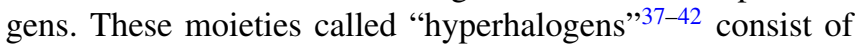
a central metal atom surrounded by superhalogen moieties. We wondered if for some specific composition polynuclear species may be the same as hyperhalogens. To illustrate this concept we concentrate on $\mathrm{Mn}_{x} \mathrm{Cl}_{y}$ systems. Since $\mathrm{MnCl}_{3}$ cluster is a superhalogen one can expect that $\mathrm{Mn}\left(\mathrm{MnCl}_{3}\right)_{x}$ $(x \geq 3)$ clusters will behave as hyperhalogens. To find out for what value of $x$ in $\mathrm{Mn}\left(\mathrm{MnCl}_{3}\right)_{x}$ clusters can also be viewed as a polynuclear species with composition $\left(\mathrm{MnCl}_{2}\right)_{y} \mathrm{Cl}$, we equate:

$$
\mathrm{Mn}\left(\mathrm{MnCl}_{3}\right)_{x}=\left(\mathrm{MnCl}_{2}\right)_{y} \mathrm{Cl} .
$$


This leads to a unique value of $x$, namely, $x=3$, i.e., $\mathrm{Mn}_{4} \mathrm{Cl}_{9}$ can be viewed either as $\left[\mathrm{Mn}\left(\mathrm{MnCl}_{3}\right)_{3}\right]$ or $\left(\mathrm{MnCl}_{2}\right)_{4} \mathrm{Cl}$. In previous work neither theoretical calculations nor experimental measurements of photo-electron spectra were performed for $\mathrm{Mn}_{4} \mathrm{Cl}_{9}$. Since the additional electron in $\mathrm{Mn}_{4} \mathrm{Cl}_{9}{ }^{-}$could not be photodetached with the $6.4 \mathrm{eV}$ laser, it suggests that the electron affinity of $\mathrm{Mn}_{4} \mathrm{Cl}_{9}$ must be higher than $6.4 \mathrm{eV}$. To see if this is indeed the case we studied the geometries and electronic structure of neutral and negatively charged $\mathrm{Mn}_{4} \mathrm{Cl}_{9}$. We not only found its electron affinity to be higher than that of $\mathrm{Cl}$, but that it is also higher than that of $\mathrm{MnCl}_{3}$. In addition, the geometry of $\mathrm{Mn}\left(\mathrm{MnCl}_{3}\right)_{3}{ }^{-}$resembles more of a $\mathrm{Mn}$ atom at the center surrounded by three $\mathrm{MnCl}_{3}$ moieties instead of a $\left[\mathrm{MnCl}_{2}\right]_{4}$ moiety to which a $\mathrm{Cl}$ atom is attached. Thus, $\mathrm{Mn}_{4} \mathrm{Cl}_{9}$ can be classified as a hyperhalogen. It is important to note that previously discussed hyperhalogens have all consisted of three elements. Here $\mathrm{Mn}_{4} \mathrm{Cl}_{9}$ represents the first binary species having hyperhalogen behavior. In addition, $\mathrm{Mn}$ being a transition metal atom that carries a large magnetic moment, these hyperhalogens provide the possibility of designing molecular magnets with large electron affinities.

\section{COMPUTATIONAL METHODS}

Our calculations were carried out using GAUSSIAN 09 code. ${ }^{43}$ Geometry optimization and frequency analysis were performed at B3LYP/6-311+G* level. ${ }^{44-46}$ To search for the ground state of $\mathrm{Mn}_{4} \mathrm{Cl}_{9}$ and its anion species, we selected about 20 initial geometrical configurations and optimized each structure without any symmetry constraint. The low-lying isomers $(\Delta E<5 \mathrm{kcal} / \mathrm{mol})$ of $\mathrm{Mn}_{4} \mathrm{Cl}_{9}^{-}$were then further re-optimized for each possible spin state using the PBE0 hybrid exchange-correlation functional ${ }^{47}$ with aug-cc-pVTZ basis set ${ }^{48}$ for $\mathrm{Cl}$ and SDD basis set and pseudopotential ${ }^{49,50}$ for Mn. For comparison with earlier results, calculations were also performed for $\mathrm{Mn}_{k} \mathrm{Cl}_{2 k+1}^{-}(k=1 \sim 4)$. To validate the consistency of our results with PBE0, VDEs were calculated at the B3LYP/6-311+G*, B3LYP/6-311+G(3df), and OVGF/6$311+\mathrm{G}^{*} / / \mathrm{PBE} 0 / \mathrm{Mn} / \mathrm{SDD} / \mathrm{Cl} / \mathrm{aug}$-cc-pVTZ level. ${ }^{51-53}$ For $\mathrm{Mn}_{k} \mathrm{Cl}_{2 k+1}^{-}(k=1,2), \quad$ UHF-CCSD(T)/Mn/SDD/Cl/aug-cc-

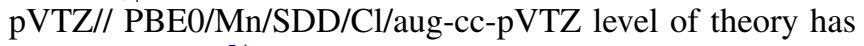
also been used ${ }^{54}$ Zero point energy (ZPE) corrections were calculated by using B3LYP/6-311+G*. We compared the experimental and theoretical VDEs for $\mathrm{Mn}_{k} \mathrm{Cl}_{2 k+1}^{-}(k=1,2)$ to confirm the reliability of our theoretical methods. The natural bond orbital (NBO) analysis ${ }^{55,56}$ was performed for bonding and charge discussions, and Gauss View 5.0.8 and VMD 1.9.1 ${ }^{57}$ were used for structure and molecular orbital (MO) visualization.

\section{RESULTS AND DISCUSSION}

We begin our discussions with the optimized structures of both the neutral and anionic $\mathrm{Mn}_{4} \mathrm{Cl}_{9}$ as shown in Figures 1 and 2. Extensive search revealed the trophy-shaped structure (Fig. 1(a)) to be the lowest energy isomer of anionic $\mathrm{Mn}_{4} \mathrm{Cl}_{9}{ }^{-}$. On the other hand, the ground-state geometry of neutral $\mathrm{Mn}_{4} \mathrm{Cl}_{9}$ completely differs from that of its anion dis-

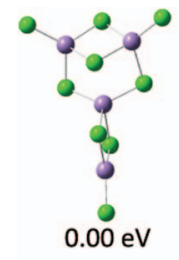

(a)

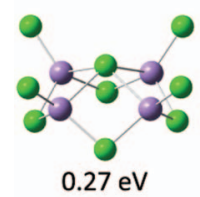

(d)

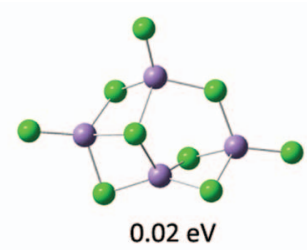

(b)

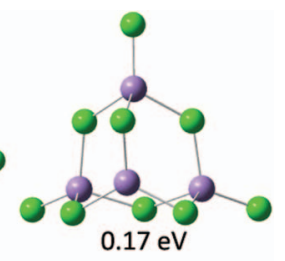

(c)

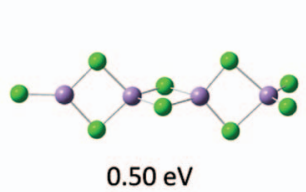

(e)

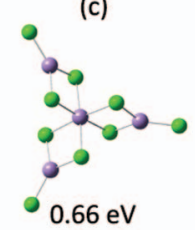

(f)

FIG. 1. Optimized geometry of isomers of the anionic $\mathrm{Mn}_{4} \mathrm{Cl}_{9}{ }^{-}$and their ZPE corrected relative energies at B3LYP/6-311+G* level.

playing an open, linear structure (Fig. 2(a)). The ground-state geometries for both neutral and anionic $\mathrm{Mn}_{4} \mathrm{Cl}_{9}$ have three $\mathrm{Mn}$ atoms with fourfold coordination while the fourth $\mathrm{Mn}$ atom is threefold coordinated.

To refine the geometries of the isomers, optimizations at $\mathrm{PBE} 0 / \mathrm{Mn} / \mathrm{SDD} / \mathrm{Cl} / \mathrm{aug}$-cc-pVTZ were carried out. Three energetically degenerate structures were found as shown in Figure 3, where the trophy-shaped structure (Fig. 3(a)) is again the lowest-energy configuration; the second isomer has nearly the same energy $(\Delta E=0.01 \mathrm{eV})$ and the third one is only $0.06 \mathrm{eV}$ higher in energy as compared to the first one. The magnetic couplings between $\mathrm{Mn}$ atoms in all the three structures are antiferromagnetic, resulting in the total magnetic moments of $0 \mu_{\mathrm{B}}$. The ground-state structure of anionic $\mathrm{Mn}_{4} \mathrm{Cl}_{9}$ has $C_{1}$ symmetry, where $\mathrm{Mn}-\mathrm{Mn}$ distance is different for the different spin orientations. The low-lying isomer (Figure 3(c)) has $\mathrm{C}_{2 \mathrm{v}}$ symmetry having a diamond-like shape. Based on our calculations, we found that the smaller 6-311G basis sets would underestimate the spin magnetic moments. Therefore, we used PBE0/Mn/SDD/Cl/aug-cc-pVTZ for magnetic moment and orbital analyses.

The Mulliken atomic spin density distribution for the ground-state structures of anionic $\mathrm{Mn}_{4} \mathrm{Cl}_{9}$ as well as neutral $\mathrm{Mn}_{4} \mathrm{Cl}_{9}$ are given in Figure 4, indicating that the majority of the spin moments reside on the four $\mathrm{Mn}$

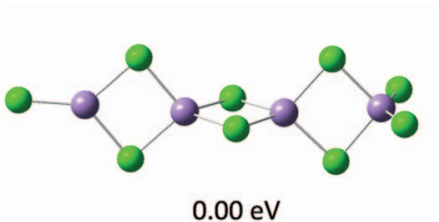

(a)

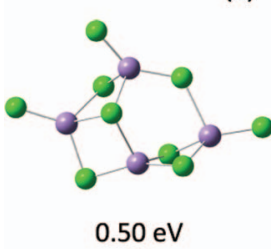

(c)

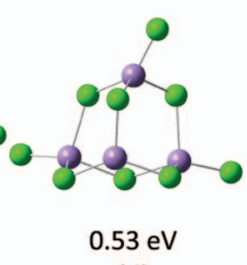

(d)

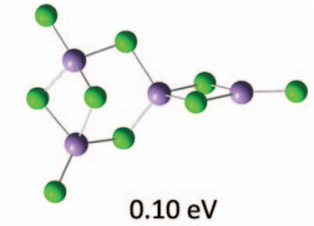

(b)

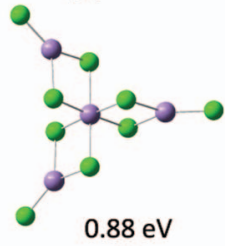

(e)

FIG. 2. Optimized structures of isomers of the neutral $\mathrm{Mn}_{4} \mathrm{Cl}_{9}$ and their $\mathrm{ZPE}$ corrected relative energies at B3LYP/6-311+G* level. 


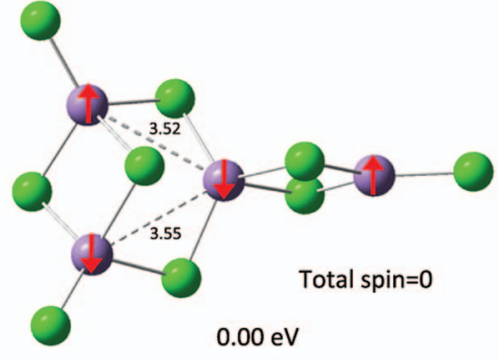

(a)

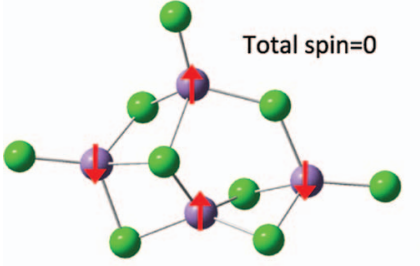

$0.01 \mathrm{eV}$

(b)

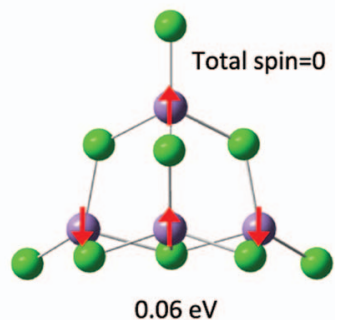

(c)
FIG. 3. Re-optimized structures of three energetically nearly degenerate isomers of the anionic $\mathrm{Mn}_{4} \mathrm{Cl}_{9}$ and their $\mathrm{ZPE}$ corrected relative energies at $\mathrm{PBE} 0 / \mathrm{Mn} / \mathrm{SDD} / \mathrm{Cl} / \mathrm{aug}-\mathrm{cc}-\mathrm{pVTZ}$. The arrows indicate the direction of local spin moments.

atoms. As stated above, the spin coupling in anionic $\mathrm{Mn}_{4} \mathrm{Cl}_{9}$ is antiferromagnetic, where the four $\mathrm{Mn}$ atoms carry magnetic moments of $5.00 \mu_{\mathrm{B}},-5.12 \mu_{\mathrm{B}}, 5.03 \mu_{\mathrm{B}}$, and $-5.02 \mu_{\mathrm{B}}$, respectively. We note that in $\mathrm{Mn}_{4} \mathrm{Cl}_{9}^{-}$, the corresponding $\alpha$ spin electron configurations of the four $\mathrm{Mn}$ atoms are $[\mathrm{Ar}] 4 s^{0.19} 3 d^{4.94} 4 p^{0.21},[\mathrm{Ar}] 4 s^{0.14} 3 d^{0.43} 4 p^{0.28}$, $[\mathrm{Ar}] 4 s^{0.18} 3 d^{4.91} 4 p^{0.27}$, and $[\mathrm{Ar}] 4 s^{0.13} 3 d^{0.35} 4 p^{0.23}$, while the $\beta$ spin electron configurations of the four $\mathrm{Mn}$ atoms are $[\mathrm{Ar}] 4 s^{0.13} 3 d^{0.29} 4 p^{0.19}, \quad[\mathrm{Ar}] 4 s^{0.17} 3 d^{4.85} 4 p^{0.30}$, $[\mathrm{Ar}] 4 s^{0.15} 3 d^{0.35} 4 p^{0.25}$, and $[\mathrm{Ar}] 4 s^{0.19} 3 d^{4.91} 4 p^{0.28}$, respectively. It is therefore clear that although the main contributions to the moments come from $3 d$ orbitals, due to the $s-p-d$ hybridization, the $4 s$ and $4 p$ orbitals are slightly polarized,

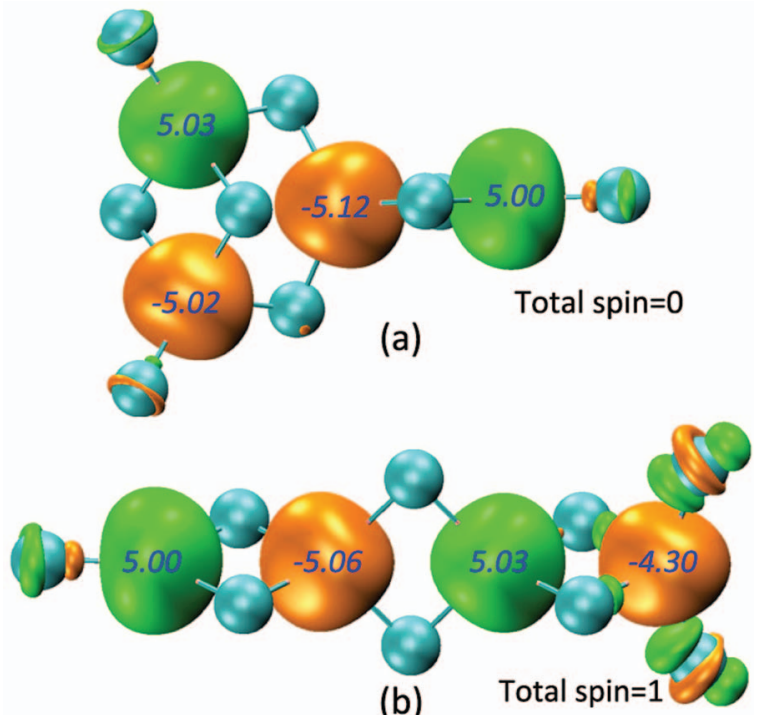

FIG. 4. Spin density distribution in (a) $\mathrm{Mn}_{4} \mathrm{Cl}_{9}{ }^{-}$, (b) $\mathrm{Mn}_{4} \mathrm{Cl}_{9}$ (isosurface value is 0.005$)$. Magnetic moments $\left(\mu_{\mathrm{B}}\right)$ at the Mn sites are shown in italics.

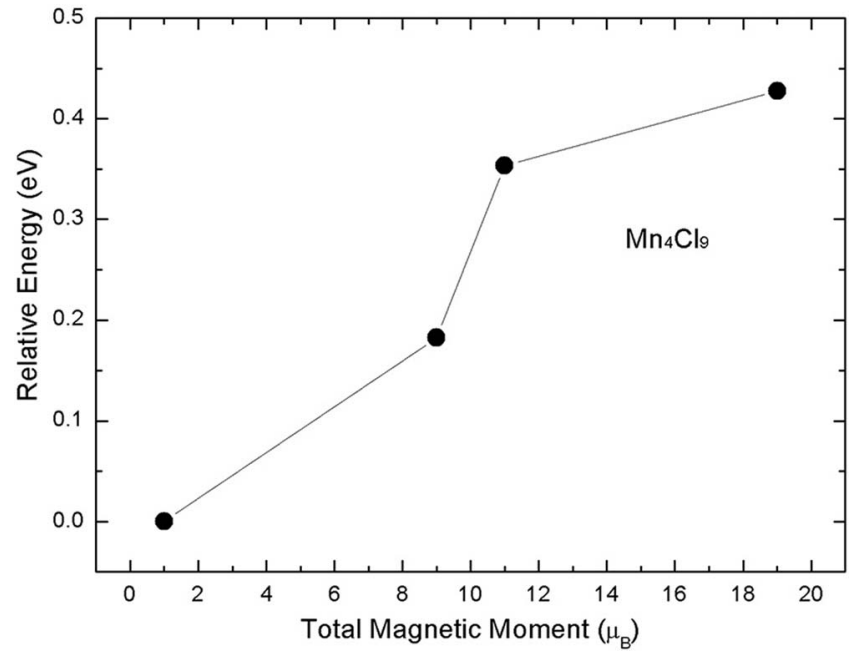

FIG. 5. Energies of neutral $\mathrm{Mn}_{4} \mathrm{Cl}_{9}$ states with different total spin given with respect to the global-minimum state.

resulting in large total magnetic moments on $\mathrm{Mn}$ sites. However, when one electron is removed from the anion, the $s-p$ - $d$ hybridization is reduced. Consequently, the spin couplings between $\mathrm{Mn}$ sites become ferrimagnetic with the total magnetic moment of $1 \mu_{\mathrm{B}}$ and the corresponding moments at the four $\mathrm{Mn}$ sites are $5.00 \mu_{\mathrm{B}},-5.06 \mu_{\mathrm{B}}$, $5.03 \mu_{\mathrm{B}}$, and $-4.30 \mu_{\mathrm{B}}$ respectively. The relative energies of $\mathrm{Mn}_{4} \mathrm{Cl}_{9}$ for different possible spin states calculated with respect to the lowest-energy spin configuration are shown in Figure 5. The doublet spin state with three AFM coupled Mn pairs is found to be the energy minimum, which is analogous to the results obtained from the previous analysis of $\mathrm{Mn}_{2} \mathrm{Cl}_{5}$ and $\mathrm{Mn}_{3} \mathrm{Cl}_{7}{ }^{36}$

From the above calculations we can see that the anionic $\mathrm{Mn}_{4} \mathrm{Cl}_{9}$ is an antiferromagnetic molecular magnet. To have further insight into its stability and the oxidation property of its neutral counterpart, we used B3LYP and PBE0 hybrid functional with various basis sets to calculate the VDEs of anionic $\mathrm{Mn}_{x} \mathrm{Cl}_{2 x+1}(x=1 \sim 4)$ clusters. Outer valence Green's function (OVGF) and coupled cluster with single and double and perturbative triple excitations (CCSD(T)) methods were also employed for comparisons. Theoretical VDEs obtained at different levels of theory are compared with experimental values of $\mathrm{Mn}_{x} \mathrm{Cl}_{2 x+1}(x=1 \sim 2)$ in Table I. Just as expected, the VDEs of anionic $\mathrm{Mn}_{x} \mathrm{Cl}_{2 x+1}(x=1 \sim 4)$ increase with the value $x$. For $x=1$, the calculated $\mathrm{VDE}$ is $5.27 \mathrm{eV}$ at the $\mathrm{PBE} 0 / \mathrm{Mn} / \mathrm{SDD} / \mathrm{Cl} /$ aug-cc-pvtz level, whereas the calculated VDE for $x=4$ is found to increase to $6.76 \mathrm{eV}$. Unfortunately, this cannot be compared with the previous experiment due to the limitation of the PES photon energy used. ${ }^{29,36}$ Our theoretical results for $x=1$ and $x=2$, however, are in good agreement with previous calculations as well as experimental PES results, ${ }^{36}$ suggesting that it is reasonable to employ DFT method within hybrid density functional to acquire theoretical VDE for anionic $\mathrm{Mn}_{4} \mathrm{Cl}_{9}$. As can be seen, the VDEs for all the anionic $\mathrm{Mn}_{x} \mathrm{Cl}_{2 x+1}(x=1 \sim 4)$ species greatly exceed the EA of chlorine atom and thus may be classified as superhalogens. However, they do not belong to conventional superhalogens and can be considered as $\left(\mathrm{MnCl}_{2}\right)_{x} \mathrm{Cl}$ as is pointed out in previous effort. ${ }^{36}$ 
TABLE I. Comparison between experimental and calculated VDEs values of $\mathrm{Mn}_{k} \mathrm{Cl}_{2 k+1}^{-}(k=1 \sim 4)$. All energies are in eV.

\begin{tabular}{ccccccccc}
\hline \hline & $\begin{array}{c}\text { B3LYP/ } \\
6-311 G^{*}\end{array}$ & $\begin{array}{c}\text { B3LYP/ } \\
6-311+\mathrm{G}(3 \mathrm{df})\end{array}$ & $\begin{array}{c}\text { PBE0/ } \\
6-311 \mathrm{G}^{*}\end{array}$ & $\begin{array}{c}\text { PBE0/Mn/SDD/ } \\
\text { Cl/aug-cc-pVTZ }\end{array}$ & OVGF $^{\mathrm{a}}$ & UHF-CCSD(T) $^{\mathrm{b}}$ & ROHF- CCSD(T) $^{\mathrm{c}}$ & EOMCCSD $^{\mathrm{d}}$ \\
\hline $\mathrm{MnCl}_{3}^{-}$ & 5.18 & 5.05 & 5.31 & $5.27(5.6 \pm 0.1)^{\mathrm{e}}$ & 5.65 & 5.83 & 5.68 & 5.79 \\
$\mathrm{Mn}_{2} \mathrm{Cl}_{5}^{-}$ & 6.10 & 5.98 & 6.24 & $6.21(6.3 \pm 0.1)^{\mathrm{e}}$ & 6.69 & 6.76 & $\mathrm{f}$ & $\mathrm{f}$ \\
$\mathrm{Mn}_{3} \mathrm{Cl}_{7}^{-}$ & 6.37 & 6.25 & 6.54 & 6.51 & 7.18 & $\mathrm{f}$ & $\mathrm{f}$ & $\mathrm{f}$ \\
$\mathrm{Mn}_{4} \mathrm{Cl}_{9}^{-}$ & 6.61 & 6.54 & 6.77 & 6.76 & 7.24 & $\mathrm{f}$ & $\mathrm{f}$ \\
\hline \hline
\end{tabular}

${ }^{a}$ VDEs were calculated at OVGF/6-311+G*//PBE0/Mn/SDD/Cl/aug-cc-pvtz level.

${ }^{b} \mathrm{VDEs}$ were calculated at UHF-CCSD(T)/Mn/SDD/Cl/aug-cc-pvtz//PBE0/Mn/SDD/Cl/aug-cc-pvtz level.

${ }^{c} \mathrm{VDEs}$ were calculated at ROHF-CCSD(T)/Mn/SDD/Cl/aug-cc-pvtz//PBE0/Mn/SDD/Cl/aug-cc-pvtz level.

${ }^{\mathrm{d}}$ VDEs were calculated at EOMCCSD/Mn/SDD/Cl/aug-cc-pvtz//PBE0/Mn/SDD/Cl/aug-cc-pvtz level.

${ }^{\mathrm{e}} \mathrm{VDEs}$ in parentheses are experimental values. ${ }^{36}$

${ }^{\mathrm{f}} \mathrm{VDE}$ could not be calculated at this level of theory.

That the VDEs of polynuclear superhalogens become larger with the increasing core size has inspired growing interest in the search of superhalogens with extremely high VDEs for oxidation of materials with large ionization potential. Hyperhalogens also provide a means of creating species with ever increasing electron affinities, but a link between these two concepts has not yet been demonstrated. Here we present a structural-based hypothesis to elucidate the unconventionally high VDE for anionic $\mathrm{Mn}_{4} \mathrm{Cl}_{9} . \mathrm{MnCl}_{3}$ is a typical high spin superhalogen since the preferred oxidation state of $\mathrm{Mn}$ in $\mathrm{Mn}$ halides is $+2 .{ }^{35}$ If we take $\mathrm{MnCl}_{3}$ as a structural block, $\mathrm{Mn}_{2} \mathrm{Cl}_{5}$ can be understood as $\mathrm{Mn}\left(\mathrm{MnCl}_{3}\right) \mathrm{Cl}_{2}, \mathrm{Mn}_{3} \mathrm{Cl}_{7}$ as $\mathrm{Mn}\left(\mathrm{MnCl}_{3}\right)_{2} \mathrm{Cl}$, and $\mathrm{Mn}_{4} \mathrm{Cl}_{9}$ as $\mathrm{Mn}\left(\mathrm{MnCl}_{3}\right)_{3}$. In each of
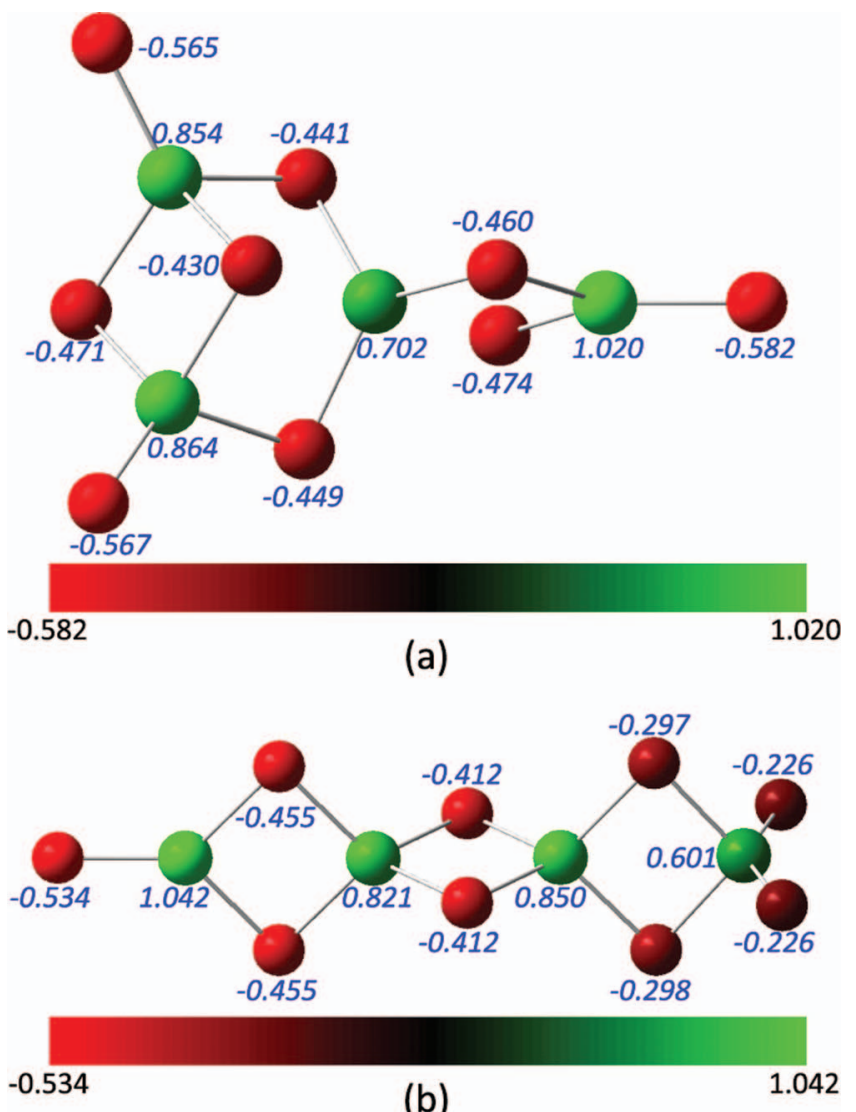

(b)

FIG. 6. NBO charge distribution of the $\mathrm{Mn}_{4} \mathrm{Cl}_{9}^{-}$(a) and $\mathrm{Mn}_{4} \mathrm{Cl}_{9}$ (b). these clusters the core is a $\mathrm{Mn}$ atom and halogen $(\mathrm{Cl})$ atoms are successively replaced by $\mathrm{MnCl}_{3}$ superhalogen moieties. Thus, it is expected that the VDE of $\mathrm{Mn}_{k} \mathrm{Cl}_{2 k+1}^{-}(k=1 \sim 4)$ increases as the number of $\mathrm{Mn}$ atoms getting larger. All these results except for $\mathrm{Mn}_{4} \mathrm{Cl}_{9}$ have been previously confirmed. If the above analysis will hold for $\mathrm{Mn}_{4} \mathrm{Cl}_{9}$ it can be classified as a hyperhalogen composed of only two elements. We define such kind of hyperhalogens as binary hyperhalogen because there is only one element acting as both the central atom of the hyperhalogen and the central atom of the superhalogen moieties.

It is therefore appropriate to presume that the groundstate geometry for anionic $\mathrm{Mn}_{4} \mathrm{Cl}_{9}$ involves a central $\mathrm{Mn}$ atom chelated by three $\mathrm{MnCl}_{3}$ blocks with every $\mathrm{MnCl}_{3}$ fragment providing two $\mathrm{Cl}$ bridging atoms, forming a highly symmetric octahedral structure. However, based on B3LYP calculation, the octahedral form (Fig. 1(f)) was found to be higher in energy than the trophy-shaped framework (Fig. 1(a)) by $0.66 \mathrm{eV}$. We attribute this to an intrinsic property of central metal cation, namely, coordination number. $\mathrm{Mn}^{2+}$ is most likely to display the coordination number of 4 in its halides, ${ }^{35}$ thus preferring the $s p^{3}$ hybridization as well as tetragonal geometry. Our calculations show that the global minimum structure for the anionic $\mathrm{Mn}_{4} \mathrm{Cl}_{9}$ is determined by its hyperhalogen

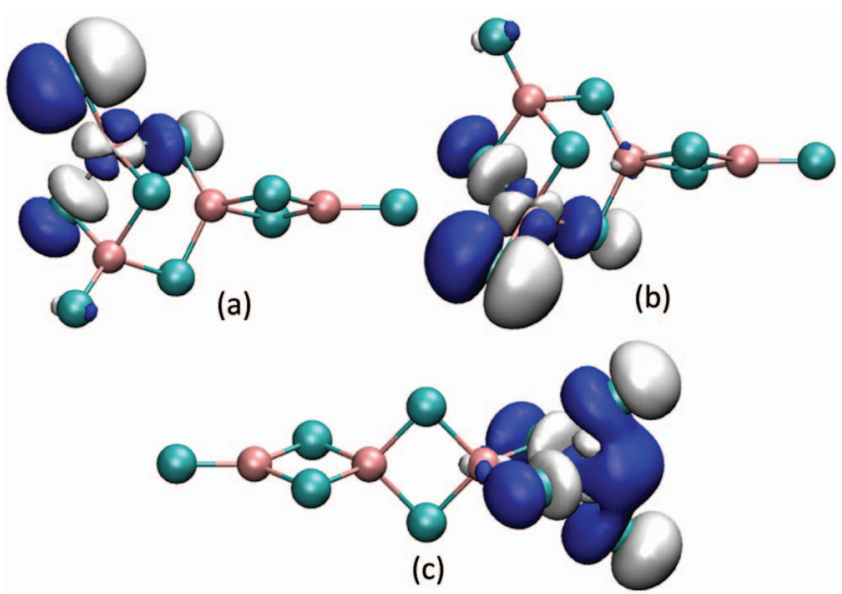

FIG. 7. Highest occupied $\alpha$ orbital (a), highest occupied $\beta$ orbital (b) of the anionic $\mathrm{Mn}_{4} \mathrm{Cl}_{9}$, and lowest unoccupied $\beta$ orbital (c) of the neutral $\mathrm{Mn}_{4} \mathrm{Cl}_{9}$. 
TABLE II. Comparison of VDEs for $\mathrm{X}^{-}$and $\mathrm{LiX}_{2}{ }^{-}\left(\mathrm{X}=\mathrm{F}, \mathrm{BO}_{2}, \mathrm{Mn}_{4} \mathrm{Cl}_{9}\right)$.

\begin{tabular}{lccccccc}
\hline \hline Anions & $\mathrm{F}^{-}$ & $\mathrm{BO}_{2}^{-}$ & $\mathrm{Mn}_{4} \mathrm{Cl}_{9}^{-}$ & $\mathrm{LiF}_{2}^{-}$ & $\mathrm{LiFBO}_{2}^{-}$ & $\mathrm{Li}\left(\mathrm{BO}_{2}\right)_{2}^{-}$ & $\mathrm{Li}\left(\mathrm{Mn}_{4} \mathrm{Cl}_{9}\right)_{2}^{-}$ \\
\hline $\operatorname{VDE}(\mathrm{eV})$ & 3.65 & 4.14 & 6.76 & 5.44 & 5.66 & 5.80 & 7.26 \\
\hline \hline
\end{tabular}

nature as well as the coordination number of $\mathrm{Mn}^{2+}$. Thus, the $\mathrm{Mn}_{4} \mathrm{Cl}_{9}$ is different from the conventional hyperhalogens.

In order to have a better understanding of the nature of bonding and electronic structure in the neutral and negatively charged $\mathrm{Mn}_{4} \mathrm{Cl}_{9}$, we calculated the electron distribution by analyzing the NBO charge. The results for neutral and anionic $\mathrm{Mn}_{4} \mathrm{Cl}_{9}$ are presented in Figure 6. We can clearly see that the charges on all the Mn atoms are positive while they are negative on all the $\mathrm{Cl}$ atoms, resulting from the anticipated $\mathrm{Mn}$ to $\mathrm{Cl}$ charge transfer. However, owing to partial back electron transfer from $\mathrm{Mn}$ to $\mathrm{Cl}$, the $\mathrm{Mn}-\mathrm{Cl}$ bonds have a somewhat covalent nature. This is confirmed by the relatively smaller charges on $\mathrm{Mn}$ and $\mathrm{Cl}$ atoms compared to other metal halides. The $\mathrm{Cl}$ atoms are, therefore, slightly polarized and also carry small spin magnetic moments (Figure 4). Particularly, the central $\mathrm{Mn}$ atom in the anionic $\mathrm{Mn}_{4} \mathrm{Cl}_{9}$ and the fourfold coordinated terminal $\mathrm{Mn}$ atom in the neutral $\mathrm{Mn}_{4} \mathrm{Cl}_{9}$ involve more of their $3 d$ electrons in the $\mathrm{Mn}-\mathrm{Cl}$ interactions, as it can be seen from the smaller NBO charges compared to other Mn atoms. The total charges on all the Mn atoms in the negatively charged $\mathrm{Mn}_{4} \mathrm{Cl}_{9}$ and its neutral counterpart are $+3.44 \mathrm{e}$ and $+3.31 \mathrm{e}$, respectively. This clearly indicates that the extra electron in the anionic $\mathrm{Mn}_{4} \mathrm{Cl}_{9}$ is delocalized over the $\mathrm{Cl}$ atoms, which contributes considerably to the high VDE of anionic $\mathrm{Mn}_{4} \mathrm{Cl}_{9}$. $\mathrm{MO}$ analysis indicates that the highest occupied $\alpha$ and $\beta$ spin orbitals of anionic $\mathrm{Mn}_{4} \mathrm{Cl}_{9}$ are energetically nearly degenerate and mainly consist of the terminal $\mathrm{Cl}$ $p_{x}$ orbital and the adjacent $\operatorname{Mn} d_{x^{2}-y^{2}}$ orbital, while the lowest unoccupied $\beta$ spin orbital is mostly contributed by the fourfold coordinated terminal $\mathrm{Mn} d_{x z}$ orbital and the peripheral $\mathrm{Cl}$ $p_{x}$ orbitals, as illustrated in Figure 7.

To further explore the possibility that the $\mathrm{Mn}_{4} \mathrm{Cl}_{9}$ can serve as a building block for larger clusters, we calculated

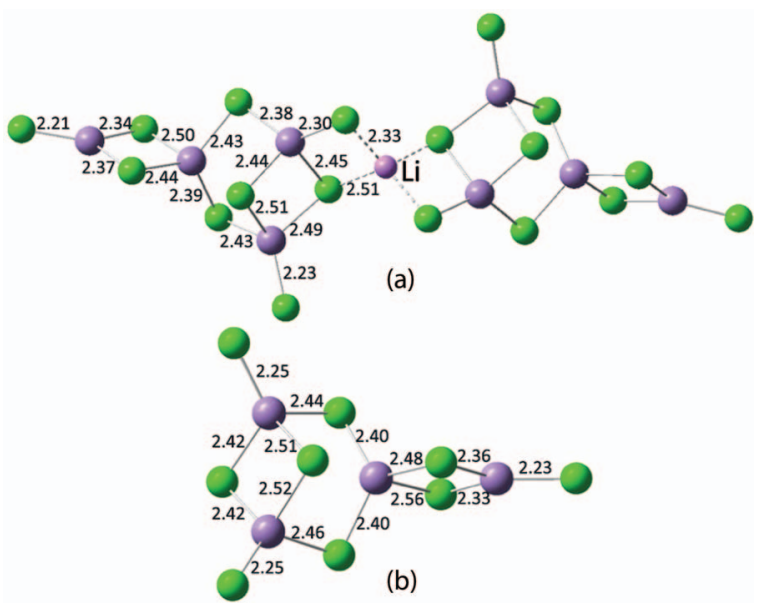

FIG. 8. Optimized geometries of $\mathrm{Li}\left(\mathrm{Mn}_{4} \mathrm{Cl}_{9}\right)_{2}^{-}$(a) and $\mathrm{Mn}_{4} \mathrm{Cl}_{9}^{-}$(b). All bond lengths are in $(\AA)$. the equilibrium structure and VDE of anionic $\mathrm{Li}\left(\mathrm{Mn}_{4} \mathrm{Cl}_{9}\right)_{2}$ cluster. The ground state geometry of anionic $\mathrm{Li}\left(\mathrm{Mn}_{4} \mathrm{Cl}_{9}\right)_{2}$ cluster (Fig. 8) is linear, where bond lengths of the two $\mathrm{Mn}_{4} \mathrm{Cl}_{9}$ fragments are nearly identical with those of the free anionic $\mathrm{Mn}_{4} \mathrm{Cl}_{9}$, indicating that the $\mathrm{Mn}_{4} \mathrm{Cl}_{9}$ anion is highly stable. We then compared the VDE of anionic $\mathrm{Li}\left(\mathrm{Mn}_{4} \mathrm{Cl}_{9}\right)_{2}$ with several other superhalogen and hyperhalogen anions to find out whether the anionic $\mathrm{Li}\left(\mathrm{Mn}_{4} \mathrm{Cl}_{9}\right)_{2}$ exhibited an ultrahyperhalogen nature. The results are given in Table II. At the same level of theory, $\mathrm{Li}\left(\mathrm{Mn}_{4} \mathrm{Cl}_{9}\right)_{2}$ anion possesses a high VDE of $7.26 \mathrm{eV}$ which is much larger than that of $\mathrm{LiF}_{2}$ or $\mathrm{Li}\left(\mathrm{BO}_{2}\right)_{2}$ anion. Furthermore, the VDE of $\mathrm{Li}\left(\mathrm{Mn}_{4} \mathrm{Cl}_{9}\right)_{2}$ anion even exceeds that of the free $\mathrm{Mn}_{4} \mathrm{Cl}_{9}$ anion, which supports the conclusion that the $\mathrm{Li}\left(\mathrm{Mn}_{4} \mathrm{Cl}_{9}\right)_{2}$ is indeed an ultrahyperhalogen. From the calculated VDEs in Table II, it is also obvious that the VDEs of the $\mathrm{LiX}_{2}^{-}$clusters increase as the ligands having higher VDEs. It is thus worth employing superhalogens or hyperhalogens as building blocks of clusters with unprecedented oxidizing property. The fragmentation energy of $\mathrm{Li}\left(\mathrm{Mn}_{4} \mathrm{Cl}_{9}\right)_{2}$ corresponding to the lowest energy pathway is $11.56 \mathrm{eV}$. Consequently, anionic $\mathrm{Li}\left(\mathrm{Mn}_{4} \mathrm{Cl}_{9}\right)_{2}$ is thermodynamically stable. Thus, it should be possible to synthesize these in experiments.

\section{CONCLUSIONS}

In summary, we have systematically studied the equilibrium geometries, magnetic couplings, vertical detachment energies, and the charge distributions of $\mathrm{Mn}_{4} \mathrm{Cl}_{9}$ and its anion by using density functional theory based calculations. The following conclusions are drawn: (1) There exists a unique composition of $\mathrm{Mn}_{x} \mathrm{Cl}_{y}$ where the cluster can be simultaneously termed as a binary hyperhalogen or a polynuclear superhalogen. In this case $\mathrm{Mn}_{4} \mathrm{Cl}_{9}$ is such a cluster. (2) The ground state geometry of $\mathrm{Mn}_{4} \mathrm{Cl}_{9}$ anion can be viewed as $\mathrm{Mn}\left(\mathrm{MnCl}_{3}\right)_{3}$ with some distortions. Since the $\mathrm{MnCl}_{3}$ behaves like a magnetic superhalogen with Mn atom carrying a magnetic moment of $5 \mu_{\mathrm{B}}, \mathrm{Mn}_{4} \mathrm{Cl}_{9}$ anion can be called a magnetic hyperhalogen. This is a unique binary system since previously studied hyperhalogens consisted of three or more elements like $\mathrm{Au}\left(\mathrm{BO}_{2}\right)_{2}$ and were not magnetic. (3) In the anionic $\mathrm{Mn}_{4} \mathrm{Cl}_{9}$, the magnetic couplings between $\mathrm{Mn}$ atoms are antiferromagnetic and each $\mathrm{Mn}$ site carries a moment of about $5 \mu_{\mathrm{B}} . \mathrm{Cl}$ sites are slightly spin polarized, sharing similar features with $\mathrm{Mn}_{2} \mathrm{Cl}_{5}$ and $\mathrm{Mn}_{3} \mathrm{Cl}_{7}$. (4) Natural bonding orbital analysis demonstrates the partial covalent nature of $\mathrm{Mn}-\mathrm{Cl}$ interactions. (5) The $\mathrm{Mn}_{4} \mathrm{Cl}_{9}$ can be used as a ligand to design ultra-hyperhalogen moieties. By varying the ligand $\mathrm{X}$ from $\mathrm{F}$ to $\mathrm{BO}_{2}$ to $\mathrm{Mn}_{4} \mathrm{Cl}_{9}$, the VDE of $\mathrm{LiX}_{2}^{-}$can be seen to steadily increase from $5.44 \mathrm{eV}$ to $5.80 \mathrm{eV}$ to $7.26 \mathrm{eV}$. We hope that our study will stimulate more experimental efforts to better understand binary hyperhalogens with varying size. 


\section{ACKNOWLEDGMENTS}

This work is supported by grants from the $\mathrm{Na}$ tional Natural Science Foundation of China (Grant Nos. NSFC-21273012 and NSFC-11174014), the National Grand Fundamental Research 973 Program of China (Grant No. 2012CB921404), and from the (U.S.) Department of Energy.

${ }^{1}$ F. Wudl, Acc. Chem. Res. 17, 227 (1984).

${ }^{2}$ A. I. Marshakov, N. P. Chebotareva, and N. B. Lukina, Prot. Met. 28, 301 (1992)

${ }^{3}$ N. Bartlett, G. Lucier, C. Shen, W. J. Casteel, Jr., L. Chacon, J. Munzenberg, and B. Žemva, J. Fluorine Chem. 71, 163 (1995).

${ }^{4}$ N. Bartlett, Proc. Chem. Soc., London 218 (1962).

${ }^{5}$ M. V. Korobov, S. V. Kuznetsov, L. N. Sidorov, V. A. Shipachev, and V. N. Mit'kin, Int. J. Mass. Spectrom. Ion Process. 87, 13 (1989).

${ }^{6}$ H. Hotop and W. C. Lineberger, J. Phys. Chem. Ref. Data 14, 731 (1985).

${ }^{7}$ G. L. Gutsev and A. I. Boldyrev, Chem. Phys. 56, 277 (1981).

${ }^{8}$ G. Gutsev and A. I. Boldyrev, Russ. Chem. Rev. 56, 519 (1987).

${ }^{9}$ G. L. Gutsev and A. I. Boldyrev, Chem. Phys. Lett. 84, 352 (1981).

${ }^{10}$ G. L. Gutsev and A. I. Boldyrev, Chem. Phys. Lett. 108, 250 (1984).

${ }^{11}$ G. L. Gutsev and A. I. Boldyrev, J. Phys. Chem. 94, 2256 (1990).

${ }^{12}$ V. G. Zakrzewski and A. I. Boldyrev, J. Chem. Phys. 93, 657 (1990).

${ }^{13}$ G. L. Gutsev, Chem. Phys. Lett. 184, 93 (1991).

${ }^{14}$ J. V. Ortiz, J. Chem. Phys. 99, 6727 (1993).

${ }^{15}$ G. L. Gutsev, R. J. Bartlett, A. I. Boldyrev, and J. Simons, J. Chem. Phys. 107, 3867 (1997).

${ }^{16}$ G. L. Gutsev, P. Jena, and R. J. Bartlett, Chem. Phys. Lett. 292, 289 (1998).

${ }^{17}$ I. Anusiewicz and P. Skurski, Chem. Phys. Lett. 358, 426 (2002).

${ }^{18}$ S. T. Arnold, T. M. Miller, and A. A. Viggiano, Int. J. Mass Spectrom. 218, 207 (2002).

${ }^{19}$ I. Anusiewicz, M. Sobczyk, I. Dabkowska, and P. Skurski, Chem. Phys. 291, 171 (2003).

${ }^{20}$ M. Sobczyk, A. Sawicka, and P. Skurski, Eur. J. Inorg. Chem. 2003, 3790 (2003).

${ }^{21}$ C. Sikorska, S. Smuczynska, P. Skurski, and I. Anusiewicz, Inorg. Chem. 47, 7348 (2008).

${ }^{22}$ S. Smuczynska and P. Skurski, Chem. Phys. Lett. 452, 44 (2008).

${ }^{23}$ X.-B. Wang, C.-F. Ding, L.-S. Wang, A. I. Boldyrev, and J. Simons, J. Chem. Phys. 110, 4763 (1999).

${ }^{24}$ X.-B. Wang and L.-S. Wang, J. Phys. Chem. A 104, 4429 (2000).

${ }^{25}$ X.-B. Wang and L.-S. Wang, J. Chem. Phys. 113, 10928 (2000).

${ }^{26}$ G. L. Gutsev, P. Jena, H.-J. Zhai, and L.-S. Wang, J. Chem. Phys. 115, 7935 (2001)

${ }^{27}$ D. E. Bergeron, A. W. Castleman, T. Morisato, and S. N. Khanna, Science 304, 84 (2004).
${ }^{28}$ B. M. Elliott, E. Koyle, A. I. Boldyrev, X.-B. Wang, and L.-S. Wang, J. Phys. Chem. A 109, 11560 (2005).

${ }^{29}$ J. Yang, X.-B. Wang, X.-P. Xing, and L.-S. Wang, J. Chem. Phys. 128, 201102 (2008).

${ }^{30}$ Y.-L. Wang, X.-B. Wang, X.-P. Xing, F. Wei, J. Li, and L.-S. Wang, J. Phys. Chem. A 114, 11244 (2010).

${ }^{31}$ A. N. Alexandrova, A. I. Boldyrev, Y.-J. Fu, X. Yang, X.-B. Wang, and L.-S. Wang, J. Chem. Phys. 121, 5709 (2004).

${ }^{32}$ I. Anusiewicz and P. Skurski, Chem. Phys. Lett. 440, 41 (2007).

${ }^{33}$ I. Anusiewicz, Aust. J. Chem. 61, 712 (2008).

${ }^{34}$ S. Freza and P. Skurski, Chem. Phys. Lett. 487, 19 (2010).

${ }^{35}$ K. Pradhan, G. L. Gutsev, C. A. Weatherford, and P. Jena, J. Chem. Phys. 134, 234311 (2011).

${ }^{36}$ M. M. Wu, H. Wang, Y. J. Ko, Q. Wang, Q. Sun, B. Kiran, A. K. Kandalam, K. H. Bowen, and P. Jena, Angew. Chem., Int. Ed. 50, 2568 (2011).

${ }^{37}$ M. Willis, M. Goetz, A. K. Kandalam, G. F. Gantefoer, and P. Jena, Angew. Chem., Int. Ed. 49, 8966 (2010).

${ }^{38}$ M. Goetz, M. Willis, A. K. Kandalam, G. F. Gantefoer, and P. Jena, ChemPhysChem 11, 853 (2010).

${ }^{39}$ Y. Feng, H.-G. Xu, W. Zheng, H. Zhao, A. K. Kandalam, and P. Jena, J. Chem. Phys. 134, 094309 (2011).

${ }^{40}$ C. Paduani, M. M. Wu, M. Willis, and P. Jena, J. Phys. Chem. A 115, 10237 (2011).

${ }^{41}$ B. Pathak, D. Samanta, R. Ahuja, and P. Jena, ChemPhysChem 12, 2423 (2011).

${ }^{42}$ K. Pradhan and P. Jena, J. Chem. Phys. 135, 144305 (2011).

${ }^{43}$ M. J. Frisch, G. W. Trucks, and H. B. Schlegel et al., GAUSSIAN 09, Revision C.01, Gaussian, Inc., Wallingford, CT, 2010.

${ }^{44}$ A. D. Becke, J. Chem. Phys. 98, 5648 (1993).

${ }^{45}$ R. Krishnan, J. S. Binkley, R. Seeger, and J. A. Pople, J. Chem. Phys. 72, 650 (1980)

${ }^{46}$ A. D. McLean and G. S. Chandler, J. Chem. Phys. 72, 5639 (1980).

${ }^{47}$ C. Adamo and V. Barone, J. Chem. Phys. 110, 6158 (1999).

${ }^{48}$ R. A. Kendall, J. Thom H. Dunning, and R. J. Harrison, J. Chem. Phys. 96, 6796 (1992).

${ }^{49}$ P. Schwerdtfeger, M. Dolg, W. H. E. Schwarz, G. A. Bowmaker, and P. D. W. Boyd, J. Chem. Phys. 91, 1762 (1989).

${ }^{50}$ M. Dolg, U. Wedig, H. Stoll, and H. Preuss, J. Chem. Phys. 86, 866 (1987).

${ }^{51}$ V. G. Zakrzewski and J. V. Ortiz, Int. J. Quantum Chem. 53, 583 (1995).

${ }^{52}$ J. V. Ortiz, J. Chem. Phys. 89, 6348 (1988).

${ }^{53}$ V. G. Zakrzewski, O. Dolgounitcheva, and J. V. Ortiz, J. Chem. Phys. 105, 5872 (1996).

${ }^{54}$ G. D. Purvis and R. J. Bartlett, J. Chem. Phys. 76, 1910 (1982).

${ }^{55}$ A. E. Reed, L. A. Curtiss, and F. Weinhold, Chem. Rev. 88, 899 (1988).

${ }^{56}$ E. D. Glendening, A. E. Reed, J. E. Carpenter, and F. Weinhold, NBO Version 3.1.

${ }^{57}$ W. Humphrey, A. Dalke, and K. Schulten, J. Mol. Graphics 14, 33 (1996). 